\title{
How neurosurgical departments in Lombardy are getting ready to face the second wave of the COVID-19 pandemic: update from the most hit region in Italy
}

\author{
Davide Boeris $^{1}$ - Davide Colistra ${ }^{1}$ - Jacopo Falco ${ }^{1}$ (D) - Fulvio Tartara ${ }^{2} \cdot$ Giuseppe A. D'Aliberti $^{1} \cdot$ Marco M. Fontanella $^{3}$. \\ Franco Servadei ${ }^{4} \cdot$ Marco Cenzato $^{1}$
}

Received: 21 November 2020 / Accepted: 26 November 2020 / Published online: 6 January 2021

(C) The Author(s), under exclusive licence to Springer-Verlag GmbH, AT part of Springer Nature 2021

The city of Milan and the entire Italy are facing the second wave of the CoViD-19 epidemic. Today, November 20, 2020, since the beginning of the pandemic, 1,345,767 [1] people have contracted the SARS-CoV-2 over a population of $60,244,639$ [2]. Of these, 48,569 died and 520,022 were discharged. Currently, the positive subjects of which there is certainly are 777,176 in the whole of Italy. As per the same date of reference, the most affected region remains Lombardy with a total 357,663 positives of which 159,641 currently positives. Eight thousand three hundred four were hospitalized, 930 in intensive care units and more than 9000 were dead over a population of $10,060,574$.

We have learned a lot from the first course of infection. While the first wave had taken us completely unprepared, this second wave finds us ready with operational protocols [3], tried-and-tested practices in the case of positive patients and very importantly with the awareness of the level of diffusivity for the operators. The medical and nursing staff have become accustomed to dealing with positive patients and know how to act. We have now full availability of personal protective equipment that in the first wave was not in stock.

Jacopo Falco

jacopofalco910@gmail.com

1 Neurosurgery Unit, Department of Neuroscience, ASST Grande Ospedale Metropolitano Niguarda, Piazza Ospedale Maggiore 3, 20161 Milan, Italy

2 Neurosurgery Unit, Istituto Clinico Città Studi, Milan, Italy

3 Division of Neurosurgery, Department of Surgical Specialties, Radiological Sciences and Public Health, University of Brescia, Brescia, Italy

4 Department of Neurosurgery, Humanitas Research Hospital and University, Milan, Italy
The characteristics of this second phase are very different. The virus has not changed, but the availability of the means of protection on a large-scale has made the spread more controllable; many more swab tests are carried out and many more asymptomatic positives are detected than in the first wave. Therapeutic protocols have helped to reduce mortality rates since the first outbreak. The association of steroids and low molecular weight heparin and other therapies has helped in controlling symptoms and reducing mortality rates $[4,5]$.

During the first period of pandemic, we estimated that hundreds of neurosurgical interventions were not performed, which had created an alarming lengthening of waiting lists. This was due to the fact that the vast majority of neurosurgical units in the region were closed and only four hospitals were still providing Neurosurgical care in a Hub and Spoke system. In recent weeks, a recovery plan for the undelivered operating sessions was being prepared. Unfortunately, this recovery plan was stopped due to the emergent second wave. The current challenge is asking to adapt our Hospitals to the CoViD19 pandemic without stopping all surgical activities. During the lockdown period, medical needs were not met entirely in the population; during the summer period, there was an attempt to make up for the lost time [6]. Neurosurgical patients have a broad spectrum of pathologies: in addition to malignant tumors (class A +) [7], a lot of other conditions need to be treated in order to avoid a significant morbidity, such as drugresistant epilepsy, functional pathologies, "benign" tumors in which a delayed treatment can compromise oncological prognosis (i.e., low-grade gliomas), or neurological status. We have to stress that a planned neurosurgery case does not mean it is not urgent and that even the so-called "elective" surgeries should be scheduled during this second phase of pandemic.

Furthermore, there is an opposition of the population towards the possible second lockdown and the economic damage that could derive from it. The Italian GDP had a reduction of $12.8 \%$ [8] due to the lockdown in the second quarter. It is 
likely that a new national lockdown in the same forms as in March-April 2020 cannot be proposed again. The central government has decreed a light lockdown. The restrictions were imposed on the basis of 21 regional parameters that allow the identification of a color code that varies from red to orange to yellow. Red has higher movement restrictions, while yellow has fewer.

We have to take into account these general issues when we think about the reorganization of neurosurgical departments, historically linked to traumatology. The Hub system was organized in Lombardy during the lockdown period in Italy with three hub hospitals able to guarantee 24/7 acceptance of emergency cases, chosen on geographical basis covering roughly $1 / 3$ of Lombard territory each and a fourth "hub" hospital for neuro oncological patients coming from all the other departments of the region [7, 9]. This has made it possible to free up beds by concentrating the emergency activity on a few neurosurgical units.

According to the collected data in the three hubs, 542 emergencies have been managed from March 9, 2020, to May 9, 2020 , covering the full range of the neurosurgical, timedependent pathology, ranging from head trauma, spinal trauma, intracerebral hemorrhages, subarachnoid hemorrhages, and subdural hematomas (Table 1). Of the 542 patients treated at that time, 52 were positive to SARS-CoV-2. Mortality and complications were significantly more frequent in patients with CoViD-19 [10]. It is difficult to propose the same organization though, firstly, because it is probable that there will not be a total lockdown and people movement which had greatly decreased between March and April 2020 will not occur again. Consequently, the number of traumas will not be so small as in March and April and will require access to more Trauma Centers. Patients will hardly accept again not being treated for non-urgent pathologies and there will be a need for outpatient appointments for both urgent and nonurgent pathologies, while during the first wave, most of the outpatient appointments were canceled. Several authors have highlighted the issue of a delayed presentation and difficulties in access to primary care [11].

The organization of this second phase of crisis should ensure elective activity for CoViD-19 patients and for nonCoViD-19 patients with divided pathways and emergency activity.

\section{How do we do now}

All the medical doctors and nurses are screened every day at the entrance of the hospital for fever and CoViD-19 symptoms. All personnel are checked with nasal swabs and hematological tests on a regular basis. Everybody, doctors, nurses, support personnel, and patients, wears a mask, and hand disinfection is continuously performed. The neurosurgeon on duty in the Emergency Room, where urgent cases are admitted, wears FFP2 mask, eye protection, and full body cover and gloves.

Emergencies Urgent cases are checked with rapid swabs and lung CT and they are not admitted into the department until we know if they are SARS-CoV-2 positive or not. Emergency operations are performed with CoViD-19+ protocols until results are obtained. Different routes are adopted for CoViD-19 and not CoViD-19 patients, with different radiology departments, lift, operating rooms and, of course, different wards. Gray areas are identified where patients are isolated until the negativity/positivity is confirmed.

Routine cases The regional government has allowed to date 20 to $30 \%$ of elective operations to be performed as compared to normal activity in spite of an increasing number of beds which are reconverted to CoViD-19 beds. This reduced workload must include oncology cases and patients neurologically deteriorated or at risk of deterioration in the next 30 days. They can be admitted to the hospital with a negative swab obtained

Table 1 Time-dependent pathologies managed by the three hubs during 1st phase of CoViD-19 emergency

\begin{tabular}{|c|c|c|c|c|}
\hline Pathology & CoViD-19+ & Male & Female & Tota \\
\hline Other & 3 & 20 & 17 & 40 \\
\hline Aneurysm/AVM subarachnoid hemorrhage & 3 & 55 & 22 & 80 \\
\hline Abscesses & 2 & 17 & 6 & 25 \\
\hline Intracerebral hematoma & 6 & 24 & 24 & 54 \\
\hline Chronic subdural hematoma & 13 & 34 & 12 & 59 \\
\hline Subarachnoid hemorrhage (sine materia) & 1 & 3 & 2 & 6 \\
\hline Hydrocephalus & 2 & 14 & 10 & 26 \\
\hline Head trauma & 16 & 46 & 41 & 103 \\
\hline Spinal trauma & 2 & 26 & 23 & 51 \\
\hline Tumors & 3 & 61 & 25 & 89 \\
\hline Total & 52 & 305 & 185 & 542 \\
\hline
\end{tabular}


48 to $72 \mathrm{~h}$ before admission. Routine and emergency cases requiring admission to the intensive care units are tested routinely with bronco-alveolar lavage.

We have created a WhatsApp chat between all the neurosurgical units of our region to share any problem that can arise, and we have organized a weekly video-meeting between all the heads of the neurosurgical departments to share indifferent cases that have to be treated in case of no availability.

\section{Conclusions}

The impression during the first course of infection was that doctors were regaining a leading role in the organization of the health system and this renewed spirit had led doctors and nurses to a spirit of sacrifice far beyond their duty, whereas now, the lack of economic and political recognition is having a very important impact on staff behaviors. The weight of these considerations becomes even more important if we consider that we have all winter ahead and that the duration of this second wave is unaware to us all. It is becoming evident that there is a need for a new model for health and particularly for surgical specialties that could cope with elective operations as well as emergencies. The new model requires more beds, more theaters, more nurses, and generally more resources that are not easily obtained.

\section{Compliance with ethical standards}

Conflict of interest The authors declare that they have no conflict of interest.

\section{References}

1. Track Reported Cases of COVID-19 https://coronavirus.jhu.edu/ map.html (Last Access: November 20 $\left.{ }^{\text {th }}, 2020\right)$

2. Resident population in Italy. http://dati.istat.it/Index.aspx? QueryId=18548 (Last Access: November 20 ${ }^{\text {th }}, 2020$ )

3. Boeris D, Falco J, Potenza A, Colistra D, Bagnoli E, Cenzato M (2020) Workflow management for COVID-19 patients needing an urgent neurosurgical procedure. J Neurosurg Sci. https://doi.org/10. 23736/S0390-5616.20.04962-0

4. Stawicki SP, Jeanmonod R, Miller AC, Paladino L, Gaieski DF, Yaffee AQ, De Wulf A, Grover J, Papadimos TJ, Bloem C, Galwankar SC, Chauhan V, Firstenberg MS, Di Somma S, Jeanmonod D, Garg SM, Tucci V, Anderson HL, Fatimah L,
Worlton TJ, Dubhashi SP, Glaze KS, Sinha S, Opara IN, Yellapu V, Kelkar D, El-Menyar A, Krishnan V, Venkataramanaiah S, Leyfman Y, Saoud Al Thani HA, Wb Nanayakkara P, Nanda S, Cioè-Peña E, Sardesai I, Chandra S, Munasinghe A, Dutta V, Dal Ponte ST, Izurieta R, Asensio JA, Garg M (2020) The 2019-2020 novel coronavirus (severe acute respiratory syndrome coronavirus 2) pandemic: a joint American College of Academic International Medicine-World Academic Council of emergency medicine multidisciplinary COVID-19 working group consensus paper. J Glob Infect Dis https://doi.org/10.4103/jgid.jgid_86_20

5. Zangrillo A, Beretta L, Scandroglio AM, Monti G, Fominskiy E, Colombo S, Morselli F, Belletti A, Silvani P, Crivellari M, Monaco F, Azzolini ML, Reineke R, Nardelli P, Sartorelli M, Votta CD, Ruggeri A, Ciceri F, De Cobelli F, Tresoldi M, Dagna L, RovereQuerini P, Serpa Neto A, Bellomo R, Landoni G, COVID-BioB Study Group (2020) Characteristics, treatment, outcomes and cause of death of invasively ventilated patients with COVID-19 ARDS in Milan, Italy. Crit Care Resusc 22(3):200-211

6. Mathiesen T, Arraez M, Asser T, Balak N, Barazi S, Bernucci C, Bolger C, Broekman MLD, Demetriades AK, Feldman Z, Fontanella MM, Foroglou N, Lafuente J, Maier AD, Meyer B, Niemelä M, Roche PH, Sala F, Samprón N, Sandvik U, Schaller K, Thome C, Thys M, Tisell M, Vajkoczy P, Visocchi M, EANS Ethico-legal committee (2020) A snapshot of European neurosurgery December 2019 vs. March 2020: Just before and during the Covid-19 pandemic. Acta Neurochir https://doi.org/10.1007/ s00701-020-04482-8

7. Zoia C, Bongetta D, Veiceschi P, Cenzato M, DiMeco F, Locatelli D, Boeris D, Fontanella MM (2020) Neurosurgery during the COVID-19 pandemic: update from Lombardy, northern Italy. Acta Neurochir. https://doi.org/10.1007/s00701-020-04305-w

8. Italy GDP, ISTAT https://www.istat.it/it/archivio/246771\#: : text= Ne1\%20secondo\%20trimestre\%20del\%202020,del\%20secondo\% 20trimestre\%20del\%202019 (Last Access: November 20 $0^{\text {th }}, 2020$ )

9. Cenzato M, DiMeco F, Fontanella M, Locatelli D, Servadei F (2020) Neurosurgery in the storm of COVID-19: suggestions from the Lombardy region, Italy (ex malo bonum). J Neurosurg. https:// doi.org/10.3171/2020.3.JNS20960

10. Doglietto F, Vezzoli M, Gheza F, Lussardi GL, Domenicucci M, Vecchiarelli L, Zanin L, Saraceno G, Signorini L, Panciani PP, Castelli F, Maroldi R, Rasulo FA, Benvenuti MR, Portolani N, Bonardelli S, Milano G, Casiraghi A, Calza S, Fontannella MM (2020) Factors associated with surgical mortality and complications among patients with and without coronavirus disease 2019 (COVID-19) in Italy. JAMA Surg. https://doi.org/10.1001/ jamasurg.2020.2713

11. Tartara F, Cofano F, Zenga F, Boeris D, Garbossa D, Cenzato M (2020) Are we forgetting non-COVID-19-related diseases during lockdown? Acta Neurochir. https://doi.org/10.1007/s00701-02004385-8

Publisher's note Springer Nature remains neutral with regard to jurisdictional claims in published maps and institutional affiliations. 